\title{
PARENTAL HLA SHARING, FETO-MATERNAL COMPATIBILITY AND NEONATAL BIRTHWEIGHT IN FAMILIES WITH A HISTORY OF RECURRENT SPONTANEOUS ABORTION
}

\author{
D. C. KILPATRICK AND W. A. LISTON \\ Department of Transfusion Medicine and Obstetrics and Gynecology, The Royal Infirmary, \\ Edinburgh, Scotland, UK.
}

\begin{abstract}
SUMMARY
The mean birthweight of babies eventually born to couples with a history of recurrent spontaneous abortion (RSA) is allegedly lower if the parents have a high degree of HLA antigen sharing (Reznikoff-Etievant et al., 1991), but this relationship has not been independently confirmed. We have re-investigated this question by analysing data from 36 families. In 22 instances, we were able to relate birthweight directly to feto-maternal HLA compatibility for the first time in such families. We were unable to confirm any appreciable influence of paternal or feto-maternal HLA sharing on birthweight or placental weight and conclude that RSA families do not differ markedly from normal families in this respect.
\end{abstract}

KEY WORDS MHC Recurrent miscarriage Antigen sharing

\section{INTRODUCTION}

Couples experiencing recurrent spontaneous abortions (RSA) have been found to share more HLA antigens than control couples (Taylor et al., 1985; Reznikoff-Etievant et al., 1987), although the relationship is weak and fails to reach statistical significance in some studies. Two general hypothesęs have been advanced to account for this (Thomas et al., 1985): (1) the "genetic" hypothesis that there is linkage disequilibrium between HLA genes and separate recessive abortion susceptibility genes; and (2) the "immunological" hypothesis that feto-maternal histocompatibility directly contributes to an abnormal immune response to fetal antigens. Our earlier findings (Jazwinska et al., 1987) that feto-maternal HLA compatibility had little influence on pregnancy characteristics or outcome in normal couples seemed to exclude the immunological hypothesis, and independent studies supported our conclusions (MacQueen and Sanfilippo, 1984; Morgan et al., 1986).

Recently, Reznikoff-Etievant and co-workers (1991) have studied the birthweights of babies born to couples who had previously experienced recurrent miscarriage. Within this special group, significantly lower neonatal birthweights were associated with high parental HLA antigen sharing and the authors suggested that HLA effects on birthweight are more pronounced in RSA couples than in the normal population.

* Correspondence to Dr. D. C. Kilpatrick, Department of Transfusion Medicine, 2 Forrest Road, Edinburgh EH1 2QN, UK. Tel: (0)31-225 9398, Fax: (0)31-2259469. 
We therefore analysed our own data on 36 RSA couples who subsequently had a live birth to try to confirm Reznikoff-Etievant et al.'s observations. Cord blood was obtained for tissue-typing from some of those deliveries enabling us also to examine feto-maternal histocompatibility directly.

\section{MATERIALS AND METHODS}

\section{Patients}

All couples had a successful pregnancy after presenting with a history of unexplained RSA as previously defined (Kilpatrick et al., 1989); in brief, three or more consecutive miscarriages and an absence of antinuclear or antiphospholipid antibodies in the women. The patients were aged 23 to 40 (mean 30.6) years with 3 to 6 (mean 3.4) previous miscarriages, and all were caucasians domiciled in Scotland. Only three women had cytotoxic antipaternal lymphocyte antibodies at presentation and two were treated with intravenous immunoglobulin. Twenty-seven women were treated with partner-specific leukocyte immunotherapy while seven received no specific treatment as part of a randomised trial.

\section{HLA Typing}

HLA typing for all well-defined HLA-A, B and DR specificities was performed by the standard two-stage microcytotoxicity tests (Tiwari and Terasaki, 1985).

\section{Statistical Analysis}

The statistical significance of the difference between the means of data sets was determined by the Mann-Whitney U-test.

\section{RESULTS}

No influence of parental HLA antigen sharing on neonatal birthweight or placental weight was apparent in 36 successful pregnancies from couples with a previous history of RSA (Table 1). No trends exist with increasing HLA similarity, and the slight and statistically non-significant differences between the two main groups are in the opposite direction for neonatal and placental weights.

Feto-maternal compatibility data were available for 22 families (Table 2). There were no perfectly compatible (zero mismatches) feto-maternal pairs, but no trend was apparent for either birthweight or placental weight from one to three mismatches. Even the greater mean birthweight associated with 3 mismatches compared to 2 was not statistically significant $(\mathrm{p}=0.3)$, and was explicable in terms of the higher proportion of male offspring.

The possible influence of the HLA-DR locus alone was analysed separately. Only one out of 36 RSA couples shared 2 DR antigens and the birth and placental weights of the female child were $4.16 \mathrm{~kg}$ and $850 \mathrm{~g}$, respectively. Fifteen couples shared one DR antigen (and therefore half of the offspring would be expected to be DR identical with their mothers). The birthweights of those offspring (mean $\pm 1 \mathrm{SD}, 3.21 \pm 0.61 \mathrm{~kg}$ ) were not significantly lower than the birthweights (mean $\pm 1 \mathrm{SD}, 3.46 \pm 0.47 ; \mathrm{p}=0.29$ ) of 20 infants born to parents who shared no DR antigens(and therefore were all inevitably DRincompatible with their mothers). The corresponding data for the placentas were 554 
Table 1. Neonatal and Placental Weight Related to Parental HLA Antigen Sharing.

\begin{tabular}{|c|c|c|c|c|c|}
\hline \multicolumn{6}{|c|}{ No. of HLA specificities shared between parents: } \\
\hline & $\underline{0}$ & 1 & $\underline{2}$ & $\underline{3}$ & 4 \\
\hline$n=$ & 7 & 13 & 12 & 2 & 2 \\
\hline \multirow[t]{2}{*}{ Birthweight $(\mathrm{kg})^{\mathrm{a}}$} & 3.33 & 3.50 & 3.09 & 3.95 & 3.90 \\
\hline & 3.44 & 0.49 & & $30 \pm 0$ & \\
\hline \multirow[t]{2}{*}{ Placental weight $(\mathrm{g})$} & 571 & 583 & 564 & 613 & 700 \\
\hline & 578 & \pm 124 & & $89 \pm 1$ & \\
\hline Sex ratio $(M: F)$ & & :9 & & $10: 6$ & \\
\hline
\end{tabular}

a: data are presented as means or as mean $\pm 1 \mathrm{SD}$.

Table 2. Neonatal and Placental Weights Related to Feto-maternal HLA Compatibility

\begin{tabular}{|c|c|c|c|}
\hline \multicolumn{4}{|c|}{ Feto-maternal mismatches ${ }^{\mathrm{a}}$ : } \\
\hline & $\underline{1}$ & $\underline{2}$ & $\underline{3}$ \\
\hline $\mathrm{n}=$ & 3 & 11 & 8 \\
\hline Birthweight $(\mathrm{kg})^{\mathrm{b}}$ & $3.58 \pm 0.64$ & $3.26 \pm 0.55$ & $3.53 \pm 0.52$ \\
\hline Placental weight $(\mathrm{g})$ & $650 \pm 143$ & $566 \pm 138$ & $580 \pm 120$ \\
\hline Sex ratio (M:F) & $2: 1$ & $6: 5$ & $6: 2$ \\
\hline
\end{tabular}

$\pm 121 \mathrm{~g}$ and $592 \pm 115 \mathrm{~g}$, respectively. Moreover, from cord blood typing, 6 neonates were found to be DR compatible with their mothers and 16 not. The difference in birthweights $(3.17 \pm 0.58 \mathrm{~kg} \mathrm{v} 3.49 \pm 0.54 \mathrm{~kg} ; \mathrm{p}=0.3)$ was not significant, and there was no difference in mean placental weights $(583 \pm 175 \mathrm{~g} \mathrm{v} 583 \pm 118 \mathrm{~g})$. The sex ratio in the DR compatible group was $3: 3$; in the DR-incompatible group it was 11:5, M:F. 
The birthweights of the 27 children born following immunotherapy $(3.34 \pm 0.54 \mathrm{~kg})$ did not differ from those of the non-treatment group $(3.38 \pm 0.64 \mathrm{~kg})$.

\section{DISCUSSION}

Although we had shown that feto-maternal histocompatibility per se did not predispose to abortion (Jazwinska et al., 1987), we were nevertheless able to confirm Taylor et al.'s (1985) claim that sharing two or more HLA-A, B or DR antigens is a characteristic difference between populations of RSA and normal couples (Kilpatrick et al., 1989). We interpreted these observations as evidence of abortion susceptibility genes with a weak linkage to HLA (Kilpatrick et al., 1989). We did not find any influence of feto-maternal HLA compatibility on neonatal birthweight for normal couples (Jazwinska et al., 1987), but the possibility remained that RSA couples would be different.

We have now performed an analysis of the relationship between birthweight and parental HLA antigen sharing in RSA couples similar to that reported by ReznikoffEtievant et al. (1991), and extended this line of investigation by including placental weights and by investigating direct feto-maternal HLA compatibility. The latter is of major importance since it is difficult to envisage how the non-inherited paternal haplotype can influence fetal development whatever the supposed mechanism of action (other than possibly via immunisation).

The data reported here do not confirm a trend towards lower birthweight with increasing parental HLA sharing in RSA couples. However, our results are consistent with the findings of Mowbray (1988) that the distribution of birthweights of 92 babies born to RSA couples after immunotherapy was identical to that of a control population. It must be stressed that a majority of Reznikoff-Etievant et al.'s patients were also given immunotherapy, so our cohort was comparable to theirs in that respect. Moreover, the birthweight associated with our immunotherapy treated and untreated pregnancies were very similar. It is unlikely, therefore, that leukocyte immunotherapy influences birthweight.

In our earlier study involving normal couples, we found a slightly greater mean birthweight in offspring from relatively HLA incompatible pregnancies which seemed merely to reflect the proportions of male children and the differences in parity of the mothers (Jazwinska et al., 1987). In discussing this, Reznikoff-Etievant et al. ignored sex and parity considerations and claimed our data were consistent with theirs, suggesting that the effect of HLA compatibility may be more pronounced in RSA couples (Reznikoff-Etievant et al., 1991). It may be more relevant that Reznikoff-Etievant et al. made a large number of statistical comparisons but did not appear to correct their $p$ values accordingly. If so, then none of their $\mathrm{p}$ values would be significant after correction. It is also noteworthy that their data are internally inconsistent: with couples sharing one DR antigen the mean birthweight $(3495 \mathrm{~g})$ was actually higher than for those sharing no DR antigens (3404g).

The number of families we studied was small, but large enough to demonstrate that the conclusions reached by Reznikoff-Etievant et al. are not soundly based. More general conclusions must be tempered by consideration of the two conflicting hypotheses proposed to account for increased HLA sharing between RSA partners. The "immunological" hypothesis is very hard to reconcile with our data, since direct feto-maternal compatibility would be expected to show the most marked effects. However, if parental 
HLA sharing reflects a weak association with HLA linked recessive genes as we previously argued (Kilpatrick et al., 1989), then a larger group might be required to achieve statistically significant results. This "genetic" hypothesis is consistent with the findings of Christiansen et al. $(1989,1990)$ who have approached this problem from a different perspective. They studied families with an RSA proband and found the abortion rate in sisters of probands increased with increasing HLA haplotype sharing between proband and sisters (Christiansen et al., 1989). Moreover, they also noted a trend towards decreasing average birthweights of offspring of siblings (male or female) of probands with increasing HLA haplotype sharing (Christiansen et al., 1990).

The work of Ober and colleagues $(1987,1988,1992)$ on the unique Hutterite community of South Dakota may also be pertinent. Although HLA-DR sharing between spouses was associated with decreased fecundability in a subgroup of women who stopped nursing prior to their first menses, this observation was not due to an increased fetal loss rate, nor was there a statistically significant difference in birthweights between HLA-DR compatible and incompatible feto-maternal pairs.

In conclusion, our data indicate that parental HLA antigen sharing does not have a major influence on fetal growth/birthweight and RSA couples do not seem to differ from normal couples in this respect.

\section{ACKNOWLEDGEMENTS}

We thank all clinical staff who referred patients to our clinic and especially the MLSO staff of our tissue typing laboratory for help with HLA typing.

\section{REFERENCES}

Christiansen, O.B., Riison, K., Lauritsen, J.G., Grunnet, N. and Jersild, C. (1989). Association of maternal HLA haplotypes with recurrent spontaneous abortions. Tissue Antigens, 34, 190199.

Christiansen Mathiesen, O., Riisom, K., Lauritsen, J.G., Grunnet, N. and Jersild, C. (1990). HLA or HLA linked genes reduce birthweight in families affected by idiopathic recurrent abortion. Tissue Antigens, 36, 156-163.

Jazwinska, E.C., Kilpatrick, D.C., Smart, G.E. and Liston, W.A. (1987). Feto-maternal HLA compatibility does not have a major influence on human pregnancy except for lymphocytotoxin production. Clin. Exp. Immunol., 69, 116-122.

Kilpatrick, D.C., Liston, W.A., Neill, G. and Maxwell, C. (1989). Immune profile of women experiencing recurrent spontaneous abortions of unknown aetiology. Disease Markers, 7, 8794.

MacQueen, J.M. and Sanfilippo, F.P. (1984). The effect of paternal HLA compatibility on the expression of paternal haplotypes in offspring. Human Immunol., 11, 155-161.

Morgan, K., Holmes, T.M., Pazderka, F. and Dossetor, J.B. (1986). Segregation of HLA A, B haplotypes and the distribution of antigen mismatches between mother and offspring in Hutterite families. Am. J. Hum. Genet., 38, 971-977.

Mowbray, J.F. (1988). Immunology of early pregnancy. Human Reprod., 3, 79-92.

Ober, C., Simpson, J.L., Ward, M., Radvany, R.M., Andersen, R. and Elias, S. (1987). Prenatal effects of maternal-fetal HLA compatibility. Am. J. Reprod. Immunol., 15, 141-149. 
Ober, C., Elias, S., O’Brien, E., Kostyu, D.D., Hauck, W.W. and Bombard, A. (1988). HLA sharing and fertility in Hutterite couples: evidence for prenatal selection against compatible fetuses. Am. J. Reprod. Immunl., 18, 111-115.

Ober, C., Elias, S., Kostyu, D.D. and Hauck, W.W. (1992). Decreased fecudability in Hutterite couples sharing HLA-DR. Am. J. Hum. Genet., 50, 6-14.

Reznikoff-Etievant, M.F., Durieuz, I., Huchet, J., Salmon, C.L. and Netter, A. (1987). Recurrent spontaneous abortions, HLA antigen sharing in anti-paternal immunity. Immunotherapic assay. In: Chaouat, G. (Ed). Immunologie de la Reproduction: Relation Materno-Foetale. Paris: Colloque INSERM, 154, 187-202.

Reznikoff-Etievant, M.F., Bonnean, J.C., Alcalay, D., Cavelier, B., Toure, C. , Lobet, R. and Netter, A. (1991). HLA antigen sharing in couples with repeated spontaneous abortions and the birthweight of babies in successful pregnancies. Am. J. Reprod. Immunol., 25, 25-27.

Taylor, C.G., Faulk, W.P. and McIntyre, J.A. (1985). Prevention of recurrent spontaneous abortions by leukocyte transfusions. J. Roy. Soc. Med., 78, 623-627.

Thomas, M.L., Harger, J.H., Wagener, D.K., Rabin, B.S. and Gill, T.J. (1985). HLA sharing and spontaneous abortion in humans. Am. J. Obstet. Gynecol., 151, 1053-1058.

Tiwari, J.L. and Terasaki, P.I. (1985). HLA and disease associations. New York: Springer Verlag, $14-17$. 


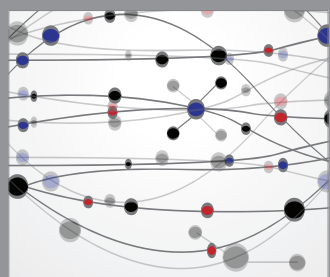

The Scientific World Journal
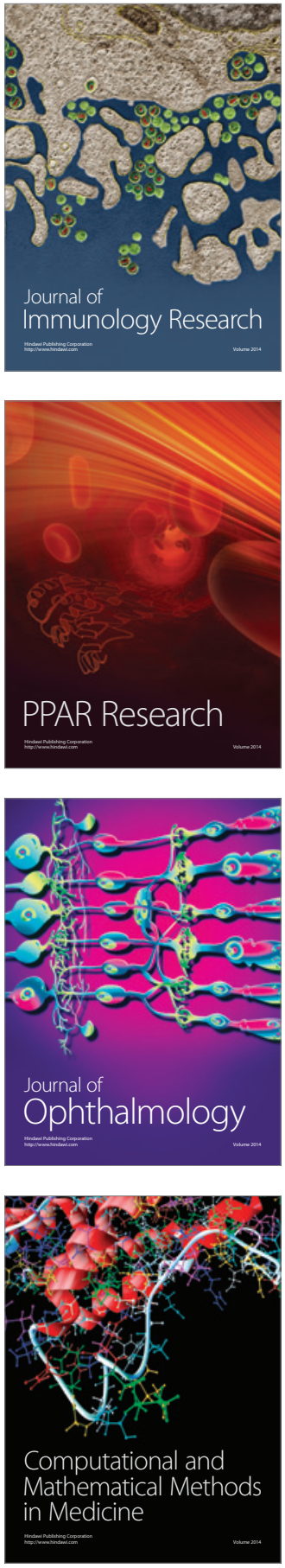

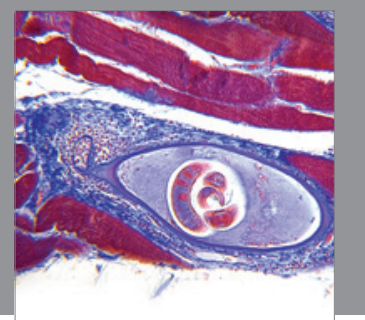

Gastroenterology

Research and Practice
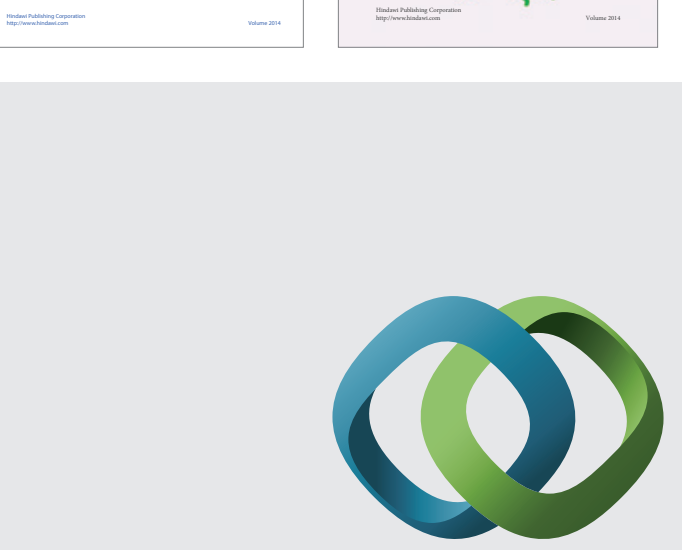

\section{Hindawi}

Submit your manuscripts at

http://www.hindawi.com
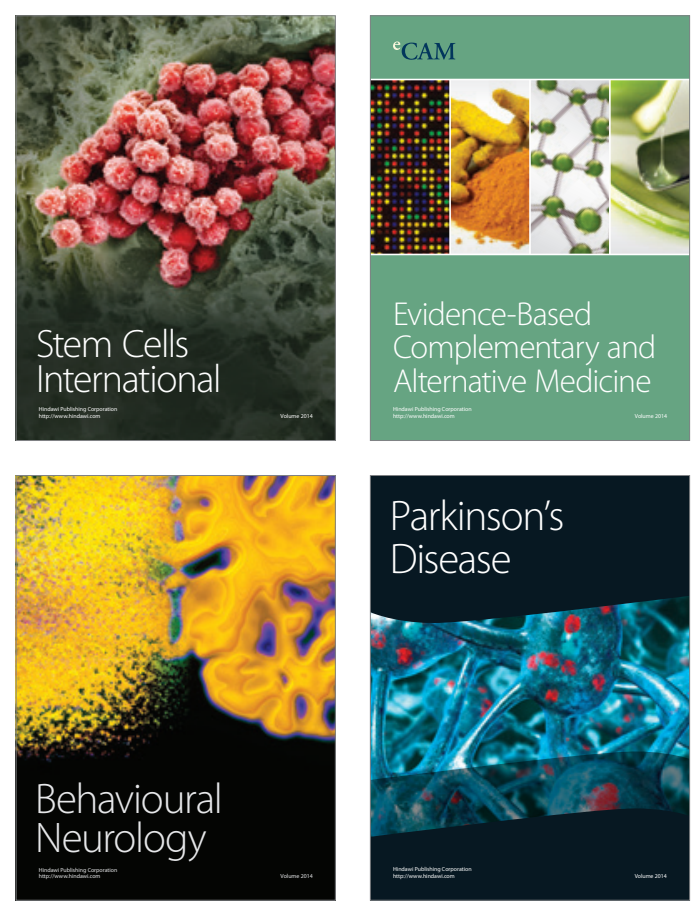

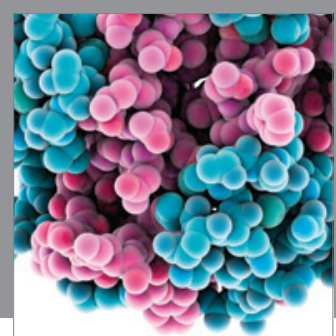

Journal of
Diabetes Research

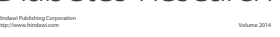

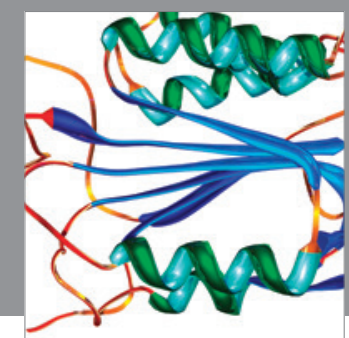

Disease Markers
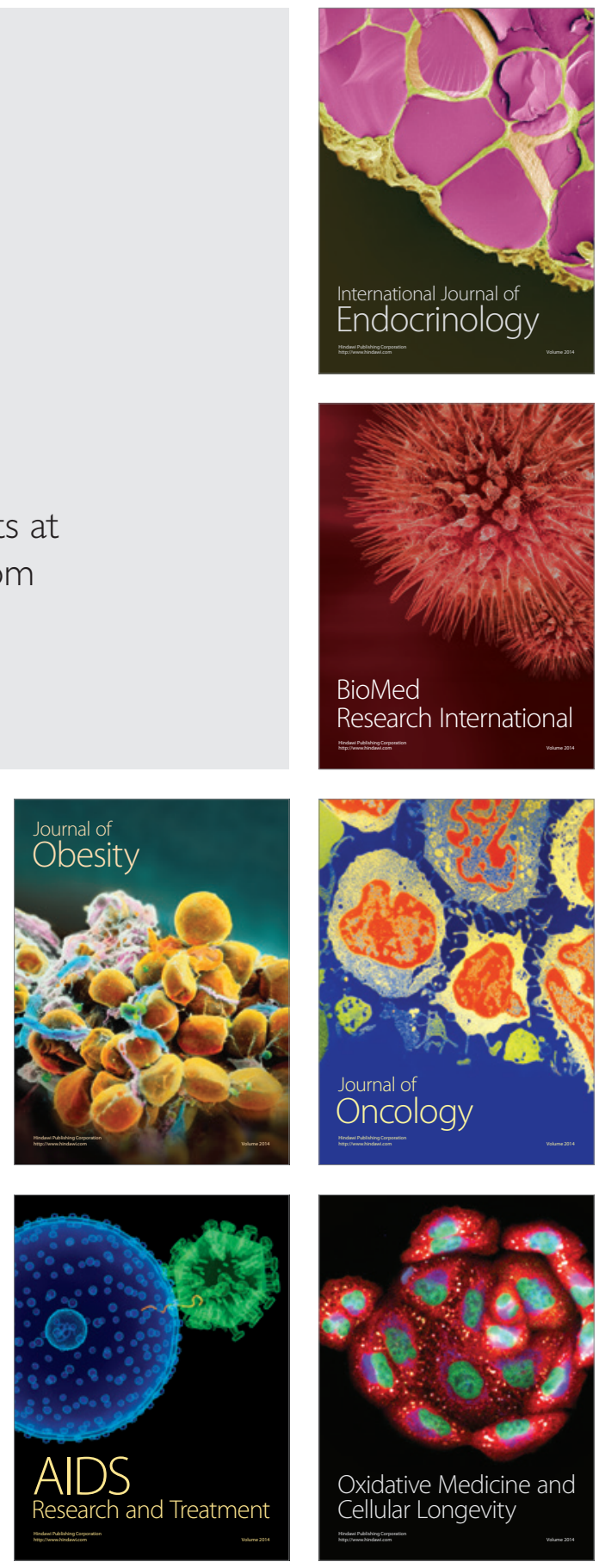